\title{
LA TRATA DE SERES HUMANOS CON FINES DE EXPLOTACIÓN SEXUAL: UNA APROXIMACIÓN DESDE LA PERSPECTIVA DE GÉNERO
}

\section{TRAFFICKING IN HUMAN BEINGS FOR THE PURPOSE OF SEXUAL EXPLOITATION: A GENDER APPROACH}

\author{
JUANA GOIZUETA VÉRTIZ1 \\ Prof. Agregada de Derecho Constitucional de la Universidad del País Vasco \\ Facultad de Derecho-Campus de Ibaeta
}

\begin{abstract}
Resumen: En el ámbito internacional, ya desde el año 1993 y en el seno de Naciones Unidas, la trata de personas con fines de explotación sexual se considera que constituye una forma de violencia de género, algo que es expresamente reconocido, también, en el Plan Integral de Lucha contra la Trata de mujeres y niñas con fines de explotación sexual que aprobó el Gobierno en 2015. El presente trabajo se centra, partiendo de dicho enfoque, en el análisis de las medidas adoptadas por el legislador de extranjería para erradicar este fenómeno delictivo cuando la víctima es la mujer extranjera en situación de irregularidad administrativa. A través de este estudio, pretendemos evidenciar la falta de perspectiva de género a la hora de abordar el tratamiento de la trata y las consecuencias que de ello se derivan para la víctima.
\end{abstract}

Palabras clave: Trata de seres humanos, explotación sexual, violencia de género, discriminación estructural, mujer inmigrante, vulnerabilidad.

Abstract: At the international level, since 1993 in the United Nations, human trafficking for the purpose of sexual exploitation is considered to constitute a form of gender-based violence, something that is also expressly recognized in the Comprehensive Plan to Combat Women and Girls Trafficking for the Purpose of Sexual Exploitation approved by the Government in 2015. Based on this approach, this paper focuses on an analysis of the measures adopted by the immigration lawmaker to eradicate this criminal phenomenon when the victim is a foreign woman in a situation of administrative irregularity. With this study, we intend to highlight the lack of a gender perspective when dealing with trafficking and the consequences for the victim.

\footnotetext{
${ }^{1}$ Este trabajo ha sido elaborado en el marco del Proyecto de Investigación de la Agencia Estatal de Investigación dedicado al "Constitucionalismo Social y Económico: nuevos retos del Estado de Derecho en Europa" (DER 2017-84195P) y del Grupo de Investigación del Gobierno Vasco sobre "Derechos Fundamentales y Unión Europea. Especial referencia al ELSJ" (IT-1190-19).
} 
Key Words: Trafficking in human beings, sexual exploitation, gender violence, structural discrimination, immigrant women, vulnerability.

\author{
Sumario: I. INTRODUCCIÓN. II. APROXIMACIÓN CONCEPTUAL A LA \\ TRATA DE PERSONAS. III. EL PLAN INTEGRAL DE LUCHA CONTRA LA \\ TRATA DE MUJERES Y NIÑAS CON FINES DE EXPLOTACIÓN SEXUAL \\ (2015-2018). IV. MARCO NORMATIVO PARA LA LUCHA CONTRA LA \\ TRATA CON FINES DE EXPLOTACIÓN SEXUAL: ESPECIAL REFERENCIA \\ A LA LEY DE EXTRANJERÍA. 1. Aproximación a la regulación prevista en el \\ Código Penal. 2. Exégesis del artículo 59 bis LOEX. V. ALGUNAS \\ REFLEXIONES FINALES. VI. BIBLIOGRAFÍA.
}

\title{
I. INTRODUCCION
}

Cualquier persona puede ser una de las víctimas de las diversas formas de criminalidad que se conocen sea ésta organizada ${ }^{2}$ o no y tenga o no naturaleza transnacional. Pero cuando en la persona confluye la condición de mujer ésta se convierte en el "blanco" principal de la trata de seres humanos y, además, de las diferentes caras con las que se nos muestra esta modalidad de actividad criminal la más dura la sufren mayoritariamente las mujeres, a saber, la trata con fines de explotación sexual $^{3}$. Una forma de delincuencia sea o no organizada que adquiere un impacto absolutamente preocupante en nuestro país tal y como lo corroboran las cifras que se aportan en las siguientes páginas.

\footnotetext{
${ }^{2}$ La Convención de Naciones Unidas contra la Delincuencia Organizada Transnacional de 15 de noviembre de 2000, define en su artículo 2 al grupo delictivo organizado como a "un grupo estructurado de tres o más personas que exista durante cierto tiempo y que actúe concertadamente con el propósito de cometer uno o más delitos graves o tipificados con arreglo a la presente Convención con miras a obtener, directa o indirectamente, un beneficio económico u otro beneficio de orden material". Con carácter previo el Consejo de la Unión Europea en la Acción Común adoptada, el 21 de diciembre de 1998, sobre la base del artículo K.3 del Tratado de la Unión Europea, relativa a la tipificación penal de la participación en una organización delictiva en los Estados miembros de la Unión Europea consideró organización delictiva a la asociación estructurada de más de dos personas, establecida durante cierto período de tiempo, y que actúa de una manera concertada con el fin de cometer delitos sancionables con una pena o medida de seguridad de privación de libertad de, al menos, cuatro años o con una pena aún más severa con independencia de que esos delitos constituyan un fin en sí mismos o un medio de obtener beneficios patrimoniales y, en su caso, de influir de manera indebida en el funcionamiento de la autoridad pública. Y el artículo 570 ter del Código Penal define al grupo criminal como "la unión de más de dos personas que, sin reunir alguna o algunas de las características de la organización criminal definida en el artículo anterior, tenga por finalidad o por objeto la perpetración concertada de delitos o la comisión concertada y reiterada de faltas". Y para un estudio más detenido sobre la conceptualización de grupo criminal, puede consultarse LUZÓN CÁNOVAS M., "La tipificación penal de la organización y el grupo criminal. Problemas concursales", Revista El Derecho, Lefebvre, 2011, págs. 1 y ss.

${ }^{3}$ En esta línea la Directiva 2011/36/UE del Parlamento Europeo y del Consejo, de 5 de abril de 2011, relativa a la prevención y lucha contra la trata de seres humanos y a la protección de las víctimas reconoce en su Exposición de Motivos que la trata afecta de manera diferente a mujeres y hombres. Y, además, en la Directiva se elimina la transnacionalita y la necesidad de delincuencia organizada como elementos necesarios para perseguir el delito de la trata.
} 
Además, el elemento de la extranjería agrava exponencialmente la violencia que sufren las mujeres víctimas de la trata con fines de explotación sexual, particularmente cuando la mujer extranjera se encuentra en una situación de irregularidad administrativa puesto que la irregularidad coloca a esta en una situación demasiado fácil y de excesivo riesgo para ser víctima de la trata con fines de explotación sexual. Téngase en cuenta que, en demasiadas ocasiones, la irregularidad está íntimamente conectada con la situación de pobreza, marginalidad e invisibilidad lo que aboca a esa mujer a una situación de especial vulnerabilidad ${ }^{4}$. Situación de fragilidad o debilidad que es consecuencia, entre otros, de los siguientes factores: la mujer inmigrante, en muchas ocasiones, se encuentra sola en el país de acogida en una situación de absoluto desarraigo: en otros supuestos, se ha visto obligada a emigrar para sostener económicamente a la estructura familiar que deja en el país de origen ante la falta de perspectivas laborales en este; un alto porcentaje de ellas carecen de una educación básica; y con demasiada frecuencia, la mujer inmigrante se encuentra con su documentación retenida ${ }^{5}$.

Es más, bien puede sostenerse que en la mayoría de los casos las víctimas de la trata con fines de explotación sexual son las mujeres extranjeras en situación de irregularidad administrativa. Para corroborar la anterior afirmación sirven los siguientes datos relativos a España: en 2013 el 34\% de las víctimas de trata identificadas son mujeres extranjeras en situación de irregularidad administrativa una cifra que alcanza el $25 \%$ en el año $2014^{6}$.

Conviene, además, no perder de vista que esta forma de criminalidad y de violencia contra la mujer implica una clara violación de los derechos humanos más elementales ${ }^{7}$ que incluso ha sido calificado de "crimen de lesa humanidad" 8 . En este sentido, siguiendo la Recomendación General núm. 19 sobre la CEDAW, en concreto la trata conlleva: la vulneración del derecho a la vida; a no ser sometido a torturas o a tratos o penas crueles, inhumanos o degradantes; a la protección en condiciones de igualdad con arreglo a normas humanitarias en tiempo de conflicto armado internacional o interno; a la libertad y la seguridad de las personas; a la protección igual de la ley; a la igualdad en la familia; al derecho al nivel más alto posible de salud física y mental; o el derecho a condiciones de empleo justas y favorables. Y es que la trata con fines de explotación sexual puede incluso conllevar la propia muerte de la víctima. En definitiva, la explotación en todas sus variantes resulta absolutamente inconciliable con la dignidad humana.

\footnotetext{
${ }^{4}$ Con SERRA CRISTÓBAL, R. y LLORIA GARCÍA, P., entendemos el concepto de vulnerabilidad en un sentido muy amplio considerando que engloba una situación administrativa precaria o ilegal, una situación de dependencia económica o un estado de salud frágil (La trata sexual de mujeres. De la represión del delito a la tutela de la víctima, Ministerio de Justicia, Madrid, 2007, en concreto, págs. 166 y ss.).

5 Téngase en cuenta que se han catalogado, entre otros, como factores de vulnerabilidad: el desconocimiento del idioma; la ausencia de documentos; y el desarraigo social o familiar (STS 910/2013, de 3 de diciembre).

${ }^{6}$ Son datos que aparecen en el Plan Integral de Lucha contra la trata de mujeres y niñas con fines de explotación sexual (2015-2018).

${ }^{7}$ ECHARRI CASI, F. J., se refiere a "una de las formas de vulneración de los derechos humanos más execrables", ("La excusa absolutoria en el delito de trata de seres humanos como mecanismo de protección de las víctimas", Diario La Ley, nº 9434, 12 de junio de 2019, pág. 2.

${ }^{8}$ MARTOS NUÑEZ, J. A., "El delito de trata de seres humanos: Análisis del artículo 177 bis del Código Penal", Estudios Penales y Criminológicos, Vol. XXXII, 2012, págs. 97 y ss.
} 
En todo caso, para una correcta contextualización, y antes de avanzar, resulta necesario constatar en este momento las 2 siguientes consideraciones. De un lado, que la trata de mujeres con fines de explotación sexual constituye una forma de violencia de género tal y como se reconoce en el contexto internacional, y en concreto, en la Resolución de la Asamblea General de Naciones Unidas 48/104, de 20 de diciembre de $1993^{9}$.

Y de otro lado, que la violencia de género -que se define en el Convenio Europeo núm. 210 sobre la prevención y la lucha contra la violencia contra las mujeres y la violencia doméstica firmado en Estambul el 11 de mayo de 2011 (en lo sucesivo Convenio de Estambul $)^{10}$ - constituye una forma o consecuencia de la discriminación sistémica que se da contra la mujer ${ }^{11} \mathrm{y}$ que se produce por la desigualdad de género existente.

Es necesario en esta sede remarcar el carácter sistémico de la discriminación contra la mujer. Resulta relevante y esclarecedora en este orden de cosas, la Declaración sobre la Eliminación de la violencia contra la mujer de Naciones Unidas de 1993 en la que se reconoce que "la violencia contra la mujer constituye una manifestación de relaciones de poder históricamente desiguales entre el hombre y la mujer, que han conducido a la dominación de la mujer y a la discriminación en su contra por parte del hombre e impedido el adelanto pleno de la mujer, y que la violencia contra la mujer es uno de los mecanismos sociales fundamentales por los que se fuerza a la mujer a una situación de subordinación respecto del hombre"12. Una naturaleza estructural de la

\footnotetext{
${ }^{9}$ Naciones Unidas en la Declaración sobre la eliminación de la violencia contra la mujer adoptada por Resolución de la Asamblea General 48/104 del 20 de diciembre de 1993 dice en el artículo 2.b) textualmente que: "Se entenderá que la violencia contra la mujer abarca los siguientes actos, aunque sin limitarse a ellos: b) la violencia física, sexual y sicológica perpetrada dentro de la comunidad en general, inclusive la violación, el abuso sexual, el acoso y la intimidación sexual en el trabajo, en instituciones educacionales y en otros lugares, la trata de mujeres y la prostitución forzada".

En el ámbito doctrinal véase por todos: SERRA CRISTOBAL, R., "La trata de mujeres como una de las formas más atroces de violencia contra la mujer", en la obra Estudio Integral de la violencia de género: Un análisis teórico práctico desde el Derecho y las Ciencias Sociales, (Martín Sánchez. M. (Dir.)), Tirant lo Blanch, Valencia, 2018, págs. 271 y ss.

${ }^{10}$ Convenio Europeo núm. 210 sobre la prevención y la lucha contra la violencia contra las mujeres y la violencia doméstica firmado en Estambul el 11 de mayo de 2011 y ratificado por España el 11 de abril de 2014.

${ }^{11}$ Discriminación contra la mujer que, según el artículo 1 de la Convención sobre la Eliminación de todas las formas de discriminación contra la mujer (CEDAW) del año 1979, se identifica con " toda distinción, exclusión o restricción basada en el sexo que tenga por objeto o resultado menoscabar o anular el reconocimiento, goce o ejercicio por la mujer, independientemente de su estado civil, sobre la base de la igualdad del hombre y de la mujer, de los derechos humanos y las libertades fundamentales en las esferas política, económica, social, cultural y civil o en cualquier otra esfera". Téngase en cuenta que la CEDAW aprobada por la Asamblea General de Naciones Unidas en su Resolución 34/180 de 18 de diciembre de 1979 constituye el principal texto legal de carácter internacional adoptado por NNUU por lo que respecta a los derechos de las mujeres. Y aunque hemos de valorar positivamente que se defina el concepto de discriminación contra la mujer, cabe sostener que hubiera sido de desear que el mismo texto hubiera explicitado que la violencia de género conforma una consecuencia de la discriminación estructural existente.

12 Resolución de la Asamblea General 48/104 del 20 de diciembre de 1993. En el mismo sentido, se manifiesta la Resolución aprobada por la Cuarta Conferencia Mundial sobre la Mujer celebrada en Beijing del 4 al 15 de septiembre de 1995 en la que se define la violencia de género como "una manifestación de las relaciones de poder históricamente desiguales entre mujeres y hombres, que han conducido a la dominación de la mujer por el hombre, la discriminación contra la mujer y a la interposición de obstáculos contra su pleno desarrollo". Y asimismo resalta este carácter estructural de la violencia contra las mujeres el Parlamento Europeo en su Resolución sobre tolerancia cero ante la
} 
violencia que también se explicita en ya mencionado Convenio de Estambul cuando se afirma que "la naturaleza estructural de la violencia contra las mujeres está basada en el género" $"$.

Así pues, la violencia contra la mujer es de carácter estructural en tanto se fundamenta en relaciones de desigualdad y subordinación de las mujeres respecto a la posición de los hombres en el contexto de una estructura social de carácter patriarcal. Y por ende, la trata es una de las formas de ejercicio de poder sobre las mujeres que ejercen los hombres. Dicho en otras palabras, la violencia contra la mujer y, asimismo, el delito de la trata es una manifestación de la discriminación estructural. De ello puede sostenerse que la explotación sexual a la que se somete a la mujer en el delito de la trata persigue perpetuar las relaciones de poder que sitúan a la mujer en una posición de subordinación respecto al hombre.

Llegados a este punto, conviene explicitar cual es el objeto de nuestro trabajo. Lo que se pretende es reflexionar sobre el tratamiento normativo que en el contexto nacional se le ha otorgado a la trata con fines de explotación sexual y, en particular, sobre las medidas adoptadas cuando la víctima es una mujer extranjera en situación irregular. A estos efectos se estudiará tanto la respuesta articulada por el legislador penal como por el de extranjería. Y con carácter previo, se hará una breve referencia al Plan Integral de lucha contra la trata de mujeres y niñas con fines de explotación sexual aprobado en el 2015 en el que podemos hallar determinadas claves que resultan interesantes para una adecuada regulación del fenómeno delictivo que es objeto de nuestra atención. Asimismo, de forma telegráfica, incluiremos algunas consideraciones que nos facilitarán la aproximación conceptual a la trata de personas. Servirá de cierre el apartado referente a las reflexiones finales.

Como corolario de este apartado, y con el objeto de aproximarnos a la magnitud que ha alcanzado la trata de personas con fines de explotación sexual consideramos que puede resultar interesante aportar algunos datos estadísticos respecto a esta forma de criminalidad y de esclavitud contemporánea. Ello, no obstante, hay que comenzar señalando que resulta harto complicado cuantificar el número de víctimas de la trata -puesto que no existe una recopilación oficial sistemática sobre datos de la trataque nos permita barajar datos reales y, por ende, conocer la dimensión o magnitud real de este delito. Es más, bien podría defenderse que uno de los mayores obstáculos con los que hemos de enfrentarnos cuando se estudia la trata es la obtención de datos fiables sobre sus dimensiones a pesar del enorme esfuerzo que se ha realizado para la obtención de datos tanto a nivel nacional como internacional. Dificultad a la que coadyuvan, en gran medida, factores tales como la dificultad de deslindar conceptualmente entre la trata de personas y el tráfico ilícito de inmigrantes o, el hecho de que, en muchas ocasiones, la víctima no denuncie el delito permaneciendo ésta en la sombra y en la más absoluta situación de invisibilidad. No obstante, creemos que, a efectos orientativos, pueden resultan ilustrativas las siguientes cifras.

La Organización Internacional del Trabajo (OIT), organismo de las Naciones Unidas encargado de formular normas laborales y atender cuestiones relacionadas con

violencia contra las mujeres de 16 de septiembre de 1997 cuando se refriere a la misma como una forma de violencia "vinculada al desequilibrio en las relaciones de poder entre los sexos en el ámbito social, económico, religioso y político" (Resolución A4-250/1997, párrafo E).

${ }^{13}$ Párrafo 11 del preámbulo del Convenio de Estambul. 
el trabajo y la protección social, calcula que en el año 2014 hay cerca de 21 millones de personas en el mundo que son víctimas de la trata de seres humanos en la que se incluye, como hemos avanzado, la trata con fines de explotación sexual en tanto régimen análogo a la esclavitud ${ }^{14}$. Llegándose a cuantificar en más de 4 millones las personas que anualmente son víctimas de la trata de personas ${ }^{15}$. En el contexto de la Unión Europea ${ }^{16}$ durante el periodo 2010-2012 el 69\% de las víctimas registradas lo fueron de la trata con fines de explotación sexual, el $80 \%$ de las víctimas de trata lo son mujeres llegando al 95\% en el caso de la trata con fines de explotación sexual, y se cifra en más de cien mil las que son víctimas de la trata cada año en la Unión Europea. Además, según EUROPOL se ha estimado que este tipo de actividad criminal representa la segunda fuente de ingresos de la delincuencia organizada después del tráfico de drogas cifrándose las ganancias que obtienen las mafias dedicadas a la trata en 32 millones de euros anuales. A lo que cabe añadir que, del análisis realizado durante el período 2010 a 2012 por la Oficina de Naciones Unidas contra la Droga y el Delito ${ }^{17}$ la explotación sexual es la forma de explotación más numerosa con un 53\% de las víctimas identificadas, que 2 de cada 3 víctimas son mujeres y que mujeres y niñas representan el $70 \%$ de las víctimas. Unas cifras que, sin duda alguna, exigen una respuesta contundente tanto desde el plano internacional como desde el estatal para luchar y erradicar esta práctica delictiva.

\section{APROXIMACIÓN CONCEPTUAL A LA TRATA DE PERSONAS}

Hay que destacar la conveniencia de realizar algunas precisiones que nos ayuden a identificar el delito de la trata de personas y ello, principalmente, porque no siempre resulta fácil diferenciar esta forma de criminalidad organizada del delito de tráfico ilícito de inmigrantes ${ }^{18}$. Una labor que se abordará de forma sucinta dada la prolija literatura sobre esta cuestión conceptual.

El Protocolo para prevenir, reprimir y sancionar la trata de personas, especialmente mujeres y niños (Protocolo de Palermo) ${ }^{19}$, que complementa la Convención de Naciones Unidas contra la Delincuencia Organizada Transnacional, en su artículo 3 a), define la trata de personas como "la captación, el transporte, el traslado, la acogida o la recepción de personas, recurriendo a la amenaza o al uso de la fuerza $\mathrm{u}$ otras formas de coacción; al rapto, al fraude, al engaño, al abuso de poder o de una

\footnotetext{
${ }^{14}$ En este sentido, en el Plan Integral de Lucha contra la Trata de mujeres y niñas con fines de explotación sexual aprobado en el año 2015 el Gobierno ha calificado la trata de seres humanos como la esclavitud de nuestro tiempo o la esclavitud del S. XXI. Una calificación que es perfectamente extensible, por lo tanto, a la trata con fines de explotación sexual. En esta línea, BALES, K., alude a la "nueva esclavitud" para referirse a la trata (La nueva esclavitud en la economía global, Siglo XXI de España Editores, 2000, pág. 13).

${ }^{15}$ Véanse los datos aportados por la OIT, en el Informe del Director General Una alianza global contra el trabajo forzoso, 2005. Conferencia Internacional del Trabajo, $93^{\mathrm{a}}$ sesión. Ginebra.

${ }^{16}$ Los datos sobre este contexto los hemos obtenido del Segundo Informe Estadístico en materia de trata del año 2014 elaborado por EUROSTAT.

${ }^{17}$ Informe Mundial sobre la Trata de personas (2014).

18 Esta dificultad de distinguir claramente entre el delito de trata de personas y el de tráfico ilícito de inmigrantes ha sido puesta de manifiesto por gran parte de la doctrina. Véase, por todos, GARCÍA VÁZQUEZ, S., "Inmigración ilegal y trata de personas en la Unión Europea: la desprotección de las víctimas", Revista de Derecho Constitucional Europeo, núm. 10/ 2008, pág. 233. Téngase en cuenta que a la mencionada confusión conceptual ayudó el hecho de que el Protocolo de Palermo se publica simultáneamente con el Protocolo que regula el tráfico ilícito de migrantes por tierra, mar y aire.

${ }^{19}$ Protocolo de Palermo ratificado por España el 21 de febrero de 2002.
} 
situación de vulnerabilidad o a la concesión o recepción de pagos o beneficios para obtener el consentimiento de una persona que tenga autoridad sobre otras, con fines de explotación. Esa explotación incluirá, como mínimo, la explotación de la prostitución ajena $\mathrm{u}$ otras formas de explotación sexual, los trabajos o servicios forzados, la esclavitud o prácticas análogas a la esclavitud, la servidumbre o la extracción de órganos" 20 . Teniendo en cuenta la delimitación conceptual de este fenómeno delictivo, podemos afirmar que la trata de personas significa "el reclutamiento, el transporte, la transferencia, acogida o el recibo de personas, por cualquier medio, para el trabajo o servicios forzado, la esclavitud o prácticas similares a la esclavitud, la servidumbre o la remoción de órganos" $"$.

Por su parte, tal y como consta en el Protocolo contra el tráfico ilícito de migrantes por tierra, mar y aire - que complementa la Convención de las Naciones Unidas contra la Delincuencia Organizada Transnacional-, el tráfico ilícito de inmigrantes se identifica con "la facilitación de la entrada ilegal de una persona en un Estado Parte del cual dicha persona no sea nacional o residente permanente, con el fin de obtener, directa o indirectamente, un beneficio financiero u otro beneficio de orden material" 22 .

De acuerdo con estas definiciones, podemos avanzar las principales diferencias que se observan entre la trata de personas y el tráfico ilícito. Las disimilitudes serían las siguientes $^{23}$. En primer lugar, en la trata de personas en tanto que exige una forma de captación indebida en la que media la coacción, el engaño o el abuso de poder se invalida el consentimiento de la víctima ${ }^{24}$, mientras que el inmigrante sí presta su consentimiento en el caso del tráfico ilícito independientemente de las condiciones en las que se produce el tráfico. En segundo lugar, la trata lleva inherente un propósito de explotación que no concurre en el supuesto del tráfico ilícito. En tercer lugar, la trata puede implicar el desplazamiento de la víctima de un lugar a otro dentro de un mismo Estado mientras que en el caso del tráfico ilícito siempre está presente el elemento de la transnacionalidad o dimensión transnacional. Y en cuarto y último lugar, el delito de la trata es de carácter personalísimo, en tanto que atenta contra los derechos humanos, mientras que en el supuesto del tráfico ilegal de inmigrantes el bien jurídico protegido es la protección de las fronteras por parte del Estado.

\footnotetext{
${ }^{20}$ En términos similares se pronuncia el legislador penal español al definir la trata de seres humanos en el art. 177.bis del Código Penal como: "La captación, el transporte, el traslado, la acogida o la recepción de personas, incluido el intercambio o transferencia de control, sobre esas personas cuando se emplee violencia, intimidación o engaño, o se abuse de una situación de superioridad o de necesidad o vulnerabilidad de una víctima, ya sea nacional o extranjera, o cuando medie la entrega o recepción de pagos o beneficios para lograr el consentimiento de la persona que posea el control sobre la víctima, con alguna de las finalidades siguientes:

a) La imposición de trabajo o servicios forzados, la esclavitud o prácticas similares a la esclavitud, a la servidumbre o a la mendicidad.

b) La explotación sexual, incluida la pornografía.

c)La explotación para realizar actividades delictivas.

d)La extracción de sus órganos corporales.

e) La celebración de matrimonios forzados".

Y en términos similares se pronuncia también el Convenio Europeo sobre la Trata de Seres Humanos ratificado por España el 2 de abril de 2009 y la Directiva 2011/36/UE.

${ }^{21}$ Véase la Guía anotada del Protocolo Completo de la ONU Contra la Trata de Personas.

${ }^{22}$ Artículo 3.a). el tráfico ilegal de inmigrantes se tipifica en el art. 318bis del CP.

${ }^{23}$ Interesante resulta en este orden de cosas la STS 214/2017, de 29 de marzo.

${ }^{24}$ A excepción de las víctimas menores de edad, donde es irrelevante el consentimiento.
} 


\section{EL PLAN INTEGRAL DE LUCHA CONTRA LA TRATA DE MUJERES Y NIÑAS CON FINES DE EXPLOTACIÓN SEXUAL (2015-2018)}

El Plan Integral de Lucha contra la trata de mujeres y niñas con fines de explotación sexual (en lo sucesivo, el Plan) aprobado por el Gobierno en el año $2015^{25}$ da respuesta a la especificidad que exige esta forma particular de violencia de género y lo hace desde una óptica integral. Este Plan, coordinado por la Delegación del Gobierno para la Violencia de Género ${ }^{26}$, viene a sustituir al anterior aprobado el 12 de diciembre del 2008 por el Consejo de Ministros ${ }^{27}$.

El Plan se inspira en las 5 prioridades previstas por la Unión Europea para erradicar la lucha contra la $\operatorname{trata}^{28} \mathrm{y}$, como apunta C. Ruiz López, supone un avance "respecto a la persecución de los sujetos activos, la asistencia a las víctimas, la formación profesional y la concienciación ciudadana" 29 . Se cifran en 7 sus principios rectores: enfoque de Derechos Humanos; perspectiva de género; primacía del interés superior del menor; mejora del conocimiento de las situaciones de trata con fines de explotación sexual; el protagonismo de las víctimas en todo el proceso; persecución del delito; y enfoque integral, cooperación y participación. Quizás el aspecto que más nos interesa desde nuestra perspectiva es el relativo al enfoque de género. Y sobre este particular, conviene subrayar las 2 siguientes consideraciones: se afirma expresamente que la trata de mujeres y niñas con fines de explotación sexual conforma una forma de violencia contra la mujer; y se deja entrever el carácter sistémico de este tipo de violencia, cuando se sostiene que esta es "consecuencia de la construcción social tanto en los países de origen como de destino, que coloca a las mujeres en una posición de desigualdad frente a los hombres".

Respecto a la estructura del Plan conviene apuntar que en él se contienen diversas partes claramente diferenciadas. Veamos, siquiera brevemente, cual es el contenido de cada una de ellas.

\footnotetext{
${ }^{25}$ Este Plan Integral (2015-2018) se encuadra dentro de la Estrategia Nacional para la erradicación de la violencia contra la mujer aprobado en el 2013 para dar respuesta al mandato que prevé el artículo 3 de la LO 1/2004, de 28 de diciembre, de Medidas de Protección Integral contra la violencia de género. En concreto, el primer párrafo del art. 3.1 dice lo siguiente: "Desde la responsabilidad del Gobierno del Estado y de manera inmediata a la entrada en vigor de esta Ley, con la consiguiente dotación presupuestaria, se pondrá en marcha un Plan Nacional de Sensibilización y Prevención de la Violencia de Género (...)"

${ }^{26}$ La Delegación del Gobierno para la Violencia de Género tiene encomendada la formulación de políticas públicas en relación con la violencia de Género según la LO 1/2004.

${ }^{27}$ Un Plan que estuvo en vigor del año 2009 al 2012 y que se complementa con las medidas contra la trata de niñas y niños incluidas en el II Plan de Acción contra la Explotación Sexual Comercial de la Infancia y la Adolescencia 2006-2009 adoptado en diciembre de 2005 por el Observatorio de la Infancia.

${ }^{28}$ Atendiendo a la Estrategia de la Unión Europea para la erradicación de la trata de seres humanos (2012-2016) las 5 prioridades mencionadas son:

“a) Detectar, proteger y asistir a las víctimas de la trata de seres humanos.

b) Reforzar la prevención de la trata de seres humanos.

c) Perseguir más activamente a los tratantes.

d) Mejorar la coordinación y cooperación entre los principales interesados y la coherencia de las políticas.

e) Conocer mejor y responder eficazmente a las nuevas tendencias relacionadas con todas las formas de trata de seres humanos".

${ }^{29}$ RUÍZ LÓPEZ, C., "La reparación en el delito de trata de seres humanos con fin de explotación sexual. Una propuesta de regulación en España”, La Ley Penal, núm. 127, julio-agosto, 2017, pág. 5.
} 
La primera parte que incluye de los apartados I a IV es descriptiva. En esta, se perfila una definición de la trata de seres humanos subrayando la necesidad de no confundirla con otras formas afines de criminalidad como es el tráfico ilegal de inmigrantes y se enfatiza en el hecho de que la trata de mujeres con fines de explotación sexual es una forma de violencia contra la mujer, se incluye la relación de las principales normas que en el ámbito internacional, europeo y nacional regulan este fenómeno y, finalmente, se fotografía la situación de la trata en España recogiéndose lo que será la base para la elaboración del presente Plan, a saber, las conclusiones y recomendaciones derivadas del seguimiento y evaluación de las políticas públicas de lucha contra la trata con fines de explotación sexual.

La segunda parte, que bien podríamos denominar parte operativa define los objetivos y las medidas del Plan. Incorporándose, asimismo, ciertas previsiones sobre la duración, la coordinación y la evaluación del Plan.

En este orden de cosas, se cifran en 10 los objetivos específicos y son 143 las medidas previstas. Y todas ellas se articular en torno a las siguientes 5 prioridades: Refuerzo de la prevención y de la detección de la trata; identificación, protección y asistencia a las víctimas de la trata; análisis y mejora del conocimiento para una respuesta eficaz a la trata con fines de explotación sexual; persecución más activa a los tratantes; $y$, coordinación y cooperación entre instituciones y participación de la sociedad civil.

El Plan entró en vigor en el año 2015 y se preveía que desplegara efectos hasta el 2018. Resulta positivo que se atribuya a la Delegación del Gobierno para la Violencia de Género la responsabilidad de la coordinación de este Plan, debiendo esta colaborar con las administraciones e instituciones implicadas en su ejecución y, en particular, se prevé la colaboración a través de la Conferencia Sectorial de Igualdad y del Foro Social contra la Trata con fines de explotación sexual. Y respecto al seguimiento y evaluación se contempla la necesidad de que impere el espíritu participativo, atribuyéndose esta labor a la Conferencia Sectorial de Igualdad y al Foro Social contra la trata con fines de explotación sexual. Un seguimiento que se realizará anualmente sobre la base de una serie de indicadores que permitan evaluar los avances conseguidos en cada una de las prioridades del Plan. A todo lo cual se añade la previsión de una evaluación final al finalizar los 4 años de vigencia del Plan que se hará utilizando, también una metodología participativa.

Conviene evidenciar que el Plan se cierra con una sección dedicada al presupuesto para la ejecución del Plan. Algo que debe valorarse muy positivamente sobre la base de que en el supuesto de documentos de carácter programático -como es este Plan contra la Trata- resulta conveniente, a nuestro parecer, cuantificar a través de cantidades globales asignadas anualmente el costo que supone la implementación de las medidas perfiladas en el Plan y prever la correspondiente dotación presupuestaria para posibilitar la efectiva realización de las actividades diseñadas.

Tras esta breve referencia al Plan, corresponde ahora analizar el marco normativo estatal previsto a los efectos de combatir el fenómeno de la trata de seres humanos, prestando especial atención a la respuesta normativa acordada por el 
legislador de extranjería tras la reforma operada por la Ley Orgánica 2/2009, de 11 de diciembre (en adelante, LOEX) ${ }^{30}$.

\section{MARCO NORMATIVO PARA LA LUCHA CONTRA LA TRATA CON FINES DE EXPLOTACIÓN SEXUAL: ESPECIAL REFERENCIA A LA LEY DE EXTRANAJERÍA}

\section{Aproximación a la regulación prevista en el Código Penal}

Tal y como hemos avanzado, nuestro centro de atención lo queremos focalizar en el estudio de aquellas medidas articuladas por el legislador español en la lucha, en particular, contra la trata de personas con fines de explotación sexual como forma de violencia de género cuando la víctima es una mujer extranjera ${ }^{31}$. Estas medidas, a las que dedicaremos las siguientes páginas, se recogen en la Ley de Extranjería (en adelante, LOEX).

Ello no obstante, no podemos obviar la relevancia que en el marco de la legislación española, adquiere el Derecho Penal cuando se trata de combatir y erradicar esta forma de delincuencia. En este sentido - y aunque no se ponga el foco exactamente en el caso de la víctima mujer inmigrante en situación irregular-, no podemos pasar por alto siquiera una breve consideración al Código Penal español. En tal orden de cosas:

Por un lado, mediante reforma operada en el año $2010^{32}$, se incluye un nuevo artículo 177 bis que queda incardinado en el Título VII bis denominado "De la trata de seres humanos"33. Una reforma que permite, siguiendo los dictados previstos en el Convenio de Varsovia, superar la confusión conceptual existente entre el delito de trata y el de favorecimiento a la inmigración ilegal. Al hilo de lo expuesto se incluye, en el apartado 1 del mencionado artículo 177.bis, una definición bastante clarificadora de este fenómeno delictivo, siendo la letra b) del apartado 1 del mencionado artículo el que contempla la explotación sexual, incluyendo la pornografía, como una de las finalidades del delito de la trata de seres humanos.

Y, por otro lado, la Ley Orgánica $1 / 2015$, de 30 de marzo, introduce en el artículo 177 bis algunas modificaciones de interés. Se incorpora el concepto de vulnerabilidad en los términos dispuestos en el texto de la Directiva 2011/36 del

\footnotetext{
${ }^{30}$ Ley Orgánica 2/2009, de 11 de diciembre, de reforma de la Ley Orgánica 4/2000, de 11 de enero, sobre derechos y libertades de los extranjeros en España y su integración social (BOE, núm. 299, de 12 de diciembre de 2009).

${ }^{31}$ Medidas de ámbito nacional que se complementan con todo aquel marco normativo adoptado a nivel internacional y europeo regulatorio de la trata de seres humanos con fines de explotación sexual, que da como resultado un conglomerado de normas, convenios y acuerdos internacionales muchos de ellos ratificados por España. En este sentido cabe mencionar, por ejemplo, el Protocolo para prevenir, reprimir y sancionar la trata de personas, especialmente mujeres y niños, que complementa la Convención de Naciones Unidas contra la Delincuencia Organizada Transnacional, ratificado por España el 21 de febrero de 2002 (BOE de 11-12-2003). Este Protocolo conocido como Protocolo de Palermo conforma el punto de partida de la acción contra la trata en el escenario internacional.

32 Ley Orgánica 5/2010, de 22 de junio, que modifica la Ley Orgánica 10/1995, de 23 de noviembre, del Código Penal (BOE núm. 152, de 23 de junio de 2010).

33 También resultan de interés, sobre este particular, entre otros, el artículo 318 bis del Código Penal. Hasta la reforma del año 2010, la trata de personas se consideraba un tipo agravado del tráfico ilegal de personas regulado en el mencionado artículo 318 bis.
} 
Parlamento Europeo y del Consejo, de 5 de abril de $2011^{34}$. Y el legislador penal añade a la vulnerabilidad la situación de necesidad, considerando que estas se dan "cuando la persona en cuestión no tiene otra alternativa, real o aceptable, que someterse al abuso" 35 . De modo que la situación de necesidad o de vulnerabilidad implican una situación de inferioridad de la víctima respecto al agresor.

Asimismo, se prevé que el reo de la trata de seres humanos será castigado con la pena superior en grado a la pena de cinco a ocho años de prisión, entre otras circunstancias, cuando la víctima sea especialmente vulnerable por razón de enfermedad, estado gestacional, discapacidad o situación personal, o sea menor de $\operatorname{edad}^{36}$.

El último párrafo del artículo 177bis, incorpora siguiendo las recomendaciones internacionales en la materia la denominada excusa absolutoria para la victima de la trata de seres humanos ${ }^{37}$. Constituye elemento esencial para que opere la excusa absolutoria el hecho de que la comisión del tipo penal sea consecuentica directa de la violencia, intimidación, engaño o abuso a la que es sometida la víctima. Una exoneración punitiva que, en suma, tal y como se manifiesta en la Exposición de Motivos de la Directiva 36/2011, persigue la salvaguardia de los derechos humanos de las víctimas, evitar una mayor victimización y animarles para que actúen como testigos.

Y no menos trascendente resulta la revisión de la regulación del decomiso ampliado del artículo 129bis incorporada, también, mediante la reforma del CP operada en 2015. Una importancia que se deriva de la posibilidad de que los bienes y efectos decomisados sean utilizados a los efectos de lograr la reparación de las víctimas, por lo que en este trabajo nos interesa, de la trata de seres humanos.

Llegados a este punto, es necesario recordar que cuando la víctima de la trata de personas con fines de explotación sexual es la mujer inmigrante en situación de irregularidad administrativa es la legislación de extranjería la que está llamada a ejercer un papel crucial en lo que respecta a la asistencia y protección de la víctima del delito, una víctima especialmente vulnerable, tal y como ya hemos avanzado. Téngase en cuenta que tal y como se recoge en las Reglas de Brasilia, sobre acceso a la justicia de las personas en condiciones de vulnerabilidad son causas que la provocan: el género, la migración, el desplazamiento el desconocimiento del idioma.

Partiendo de esta base, abordaremos en las siguientes páginas el estudio del régimen de asistencia y protección diseñado en la LOEX tras la reforma del año 2009.

\footnotetext{
${ }^{34}$ Para determinar cuándo nos situamos ante una situación de vulnerabilidad hay que tener en cuenta los indicadores de vulnerabilidad recogidos en las Reglas de Brasilia.

${ }^{35}$ Artículo 177bis 1 último párrafo.

${ }^{36}$ Artículo 177bis 4) del Código Penal.

${ }^{37} \mathrm{El}$ art. 177bis, párrafo 11 dice lo siguiente: "Sin perjuicio de la aplicación de las reglas generales de este Código, la víctima de la trata de seres humanos quedará exenta de pena por las infracciones penales que haya cometido en la situación de explotación sufrida, siempre que su participación en ellas haya sido consecuencia directa de la situación de violencia, intimidación, engaño o abuso a que haya sido sometida y que exista una adecuada proporcionalidad entre dicha situación y el hecho criminal realizado".

Para un análisis en profundidad sobre la institución de la excusa absolutoria y sus puntos fuertes y contradicciones véase ECHARRI CASI, F. J., "La excusa ...”, cit., págs. 1-26.
} 
Como es conocido, se procede a la reforma por cuarta vez, entre otras, de la LOEX, tal y como hemos avanzado, en diciembre de $2009^{38}$. Una reforma que pretende, por lo que a este tema respecta, cumplir con las obligaciones internacionales asumidas por el Estado español y adaptar nuestro Ordenamiento jurídico a la normativa comunitaria. Téngase en cuenta: por un lado, que España ha ratificado en el año 2003 el ya mencionado Protocolo de Palermo I y en el año 2009 el Convenio del Consejo de Europa sobre la lucha contra la trata de seres humanos ${ }^{39}$; y por otro lado que, ya en el año 2004, vio la luz la Directiva 2004/81/CE, del Consejo, de 29 de abril, relativa a la expedición de un permiso de residencia a nacionales de terceros países que sean víctimas de la trata de seres humanos o hayan sido objeto de una acción de ayuda a la inmigración ilegal que cooperen con las autoridades competentes ${ }^{40}$. Una Directiva que España no había procedido a transponer a su Ordenamiento interno cuando el plazo de transposición llegó a su fin el 6 de agosto de $2006^{41}$.

Antes de avanzar, conviene evidenciar que la trata de seres humanos se sitúa en el centro de atención de las instituciones comunitarias y de los Estados parte de la Unión. A esta preocupación responden, por ejemplo, la celebración de la Conferencia interministerial "Hacia una acción global de la UE contra la trata de seres humanos" celebrada en Bruselas los días 19 y 20 de octubre de 2009 así como la adopción en el Consejo Europeo de Bruselas celebrado el 10 y 11 de diciembre de 2009 del Programa de Estocolmo en el que se subraya la necesidad de dedicar los máximos esfuerzos a luchar contra las redes de trata de mujeres. Estando, además, la trata de personas prohibida en el artículo 5 de la Carta de Derechos Fundamentales de la Unión Europea y quedando ésta incardinada en el capítulo II del Título V dedicado a las políticas sobre controles en las fronteras, asilo e inmigración del Tratado de Funcionamiento de la Unión Europea tras Lisboa ${ }^{42}$.

En concreto, en el año 2009 se incorpora un nuevo artículo a la LOEX: el artículo 59bis relativo a la protección de las víctimas de la trata de personas cuando están son especialmente vulnerables como es el caso de las mujeres inmigrantes en situación irregular. Las medidas que incorpora este nuevo precepto serán objeto de nuestra atención en las siguientes páginas.

\section{Exégesis del artículo 59bis LOEX}

El legislador de extranjería, trasponiendo la ya mencionada Directiva 2004/81 y tomando como punto de referencia el Convenio del Consejo de Europa sobre la lucha

\footnotetext{
${ }^{38}$ La LOEX ya había sido previamente reformada en tres ocasiones: en concreto, por las Leyes Orgánicas $8 / 2000$, de 22 de diciembre, 11/2003, de 29 de septiembre y 14/2003, de 14 de noviembre.

${ }^{39}$ Instrumento de ratificación publicado en el BOE núm. 219, de 10 de septiembre de 2009.

${ }^{40}$ DOUE L261/19, de 6 de agosto de 2004.

${ }^{41}$ Transposición que tampoco se había producido a la fecha prevista en países como Alemania, Francia, Italia, Chipre, Luxemburgo, Portugal, Malta y Suecia. A diferencia de lo ocurrido en Estonia, Grecia, Letonia, Lituania, Hungría, Países Bajos, Austria, Polonia, Eslovenia, Eslovaquia y Finlandia que cumplieron la obligación de transposición adoptando las oportunas medidas nacionales al efecto. Hágase notar que España ha sido condenada por incumplimiento al no adoptar, dentro del plazo señalado, las disposiciones necesarias para dar cumplimiento a la Directiva 2004/81 (Sentencia del Tribunal de Justicia (Sala Sexta) de 14 de mayo de 2009, Comisión de las Comunidades Europeas contra Reino de España, Asunto C-266/08).

${ }^{42}$ Resultan de interés tanto el artículo 79 como el 83 del TFUE.
} 
contra la trata de seres humanos, incorpora a la LOEX un nuevo artículo 59bis ${ }^{43}$. Este precepto, siguiendo un esquema similar al previsto para el artículo $31 \mathrm{bis,} \mathrm{hace}$ referencia expresa a la trata de personas. Una referencia explícita que implica limitar el ámbito de aplicación subjetivo del precepto en cuestión restringiéndolo exclusivamente a las víctimas de la trata de personas. Se excluye, así, de su ámbito de aplicación subjetivo a aquellas víctimas del tráfico ilegal de personas. Veamos, a continuación, cuáles son las principales novedades que aporta la inclusión de este nuevo artículo y, en particular, cuáles se aplican específicamente a las mujeres extranjeras en situación de irregularidad administrativa lo que sin duda alguna aumenta la situación de vulnerabilidad de estas víctimas.

El apartado primero del nuevo artículo 59bis de la LOEX prevé un mandato dirigido a las autoridades competentes quienes deberán adoptar las medidas necesarias para la identificación de las víctimas de la trata de personas remitiéndose a lo previsto en el artículo 10 del Convenio del Consejo de Europa sobre la lucha contra la trata de seres humanos. De manera esquemática podemos señalar que, siguiendo el tenor literal del citado artículo $10^{44}$, se consideran medidas necesarias, entre otras, las siguientes: dotar a las autoridades competentes de personas formadas y cualificadas en labores de identificación y asistencia a las víctimas, y en especial, de las víctimas menores; asegurar la coordinación necesaria entre autoridades y organizaciones asistenciales para la correcta identificación de las víctimas; asegurar, cuando existan motivos razonables para creer que una persona ha sido víctima de trata de seres humanos, que no se traslade a la misma de su territorio hasta que las autoridades competentes hayan finalizado el proceso para su identificación como víctima; o, presumir, en caso de incertidumbre en cuanto a la edad de la víctima, y cuando existan razones para creer que se trata de un menor, que es un menor y aplicar medidas de protección especiales hasta que pueda verificarse su edad. Sobre la identificación de las víctimas hay que hacer constatar que

\footnotetext{
${ }^{43}$ Artículo que se incorpora como resultado de la presentación de una enmienda presentada por el Grupo parlamentario socialista.

${ }^{44} \mathrm{El}$ tenor literal de este artículo 10 bajo la rúbrica de "Identificación de las víctimas" preceptúa como sigue:

“1. Cada Parte dotará a sus autoridades competentes de personas formadas y cualificadas en la prevención y lucha contra la trata de seres humanos y en la identificación y asistencia a las víctimas, especialmente los menores, y se asegurará de que las distintas autoridades colaboren entre ellas y con las organizaciones responsables de prestar asistencia, con el fin de permitir la identificación de las víctimas en un procedimiento que tenga en cuenta la situación especial de las mujeres y menores víctimas y, en los casos apropiados, que se expidan permisos de residencia en las condiciones previstas en el artículo 14 del presente Convenio.

2. Cada Parte adoptará las medidas legislativas u otras medidas que sean necesarias para identificar a las víctimas con la colaboración, en su caso, de otras Partes y de las organizaciones responsables de prestar asistencia. Cada Parte se asegurará de que, si las autoridades competentes consideran que existen motivos razonables para creer que una persona ha sido víctima de trata de seres humanos, no se traslade a la misma de su territorio hasta que las autoridades competentes hayan finalizado el proceso para su identificación como víctima de una infracción prevista en el artículo 18 del presente Convenio, y se asegurarán asimismo de que esa persona reciba la asistencia prevista en los apartados 1 y 2 del artículo 12.

3. En caso de incertidumbre en cuanto a la edad de la víctima, y cuando existan razones para creer que se trata de un menor, se presumirá que es un menor y se le aplicarán medidas de protección especiales hasta que pueda verificarse su edad.

4. En el momento en que se identifique como víctima a un menor no acompañado, cada Parte:

a) Dispondrá lo necesario para que sea representado, bien por un tutor legal o por una organización o autoridad que actúe en defensa del interés superior del niño;

b) Adoptará las medidas necesarias para determinar su identidad y su nacionalidad;

c) Hará todo lo posible por encontrar a su familia, cuando ello sea en interés superior del niño".
} 
esta labor no resulta nada fácil a veces, puesto que resulta habitual que estas decidan no comunicar tal condición a las autoridades lo que es perfectamente comprensible si tenemos en cuenta las presiones que estas sufren tanto directas como sobre sus familiares. Por ello es tan importante en este ámbito la adecuada preparación de los profesionales intervinientes en el proceso, a fin de evitar la doble victimización.

El apartado segundo, por su parte, incorpora la previsión de un período de restablecimiento y reflexión para aquellos supuestos en los que se estime de forma razonable que la víctima de la trata de seres humanos es una mujer extranjera en situación irregular, remitiéndose al reglamento la concreción del procedimiento para la concesión del mencionado período. Una concreción que se realiza en los artículos 140 a 146 del Real Decreto 557/2011, de 20 de abril.

Cabe afirmar que, atendiendo a la literalidad de la ley, este período se contempla con el objetivo de otorgar un lapso de tiempo para que la víctima reflexione y medite, tras ser informada en la lengua que entienda, sobre si desea colaborar o no con las autoridades competentes en la investigación del delito $\mathrm{y}$, en su caso, en el procedimiento penal. Ello no obstante, este período de restablecimiento y reflexión, también, parece que debe de servir para que la víctima se recupere física, psicológica y emocionalmente y pueda, así, decidir si coopera con conocimiento de causa ${ }^{45}$.

Este período habrá de ser suficiente a los objetivos previstos y tendrá una duración de al menos 90 días. De modo que podrá ampliarse este plazo siempre que finalizado el período de reflexión así se aconseje tras la evaluación que las administraciones públicas realizarán de la situación personal de la víctima.

Es positivo este período si ello permite, asimismo, a la mujer extranjera en situación irregular alejarse de la influencia de los tratantes. Durante tal período, además, se autorizará la estancia temporal de la víctima en situación irregular en territorio español procediéndose a la suspensión del expediente sancionador iniciado o, en su caso, de la ejecución de la sanción ya acordada, sea la expulsión o la devolución. En concreto, el artículo 143.1 del Real Decreto 557/2011 contempla la posibilidad de que el Instructor de la causa comunique al órgano competente lo decidido sobre la eventual exención de responsabilidad a los efectos de archivar el procedimiento, de continuarlo o de revocar la medida de expulsión o devolución decretada.

De modo que el punto de partida del nuevo artículo 59bis es la incoación de un expediente sancionador, aunque lo cierto es que, se prevé la paralización del procedimiento sancionador sea cual sea la fase en la que éste se encuentra $y$, como veremos más adelante, además el precepto en cuestión contempla la posibilidad de que la autoridad competente declare a la víctima exenta de responsabilidad administrativa. En este sentido, el artículo 143.1 del Real Decreto 557/2011 contempla la posibilidad de que el Delegado o Subdelegado del Gobierno competente pueda fijar de oficio la exención de responsabilidad de la víctima atendiendo a su situación personal, lo que abre las puertas para que esta pueda cursar una solicitud de autorización de residencia y trabajo por circunstancias excepcionales.

\footnotetext{
${ }^{45}$ En concreto, el artículo 6 de la Directiva 2004/81 se refiere a un período de reflexión que permita a la víctima recuperarse y librarse de la influencia de los autores del delito, de forma que pueda decidir con conocimiento de causa si coopera con las autoridades competentes.
} 
Como puede observarse, desde el momento en que se inicia el proceso de identificación de una posible víctima de la trata con fines de explotación sexual se activan los mecanismos para proteger a esta de cualquier medida sancionadora que vaya ligada a su situación de irregularidad en el país. Así pues, la exención de la sanción administrativa se liga a la denuncia del hecho delictivo.

Debe hacerse notar, asimismo, que durante el período de restablecimiento y reflexión es necesario procurar por parte de la Administración los recursos necesarios para la asistencia y protección de la víctima. Una previsión de indudable transcendencia habida cuenta que en el caso de la trata de personas la víctima padece un miedo o pánico, en muchos casos, insuperable a sufrir represalias tanto por parte del autor del delito como de su entorno más próximo ${ }^{46}$. Represalias que pueden, incluso, llegar a influir en el testimonio que ésta ha de prestar en el procedimiento judicial como una evidencia más de la especial situación de vulnerabilidad en la que se encuentra la mujer inmigrante en situación irregular que es víctima de este tipo de delitos. Y entendemos que esta obligación que pesa sobre la Administración ha de incluir una atención integral de la mujer inmigrante víctima del delito que exige la actuación conjunta de diversos profesionales y la facilitación de diversos servicios. Entre otros, alojamiento seguro, atención sanitaria ${ }^{47}$, atención psicológica, atención psiquiátrica, intérpretes, mediadores culturales, agentes de los cuerpos y fuerzas de seguridad del Estado o asistencia jurídica $^{48}$. En esta línea el artículo 140 del Real Decreto 557/2011 apuesta por la adopción de un Protocolo Marco de protección de Víctimas de trata de seres humanos en el que se establezcan las bases de la coordinación y actuación conjunta de las instituciones y administraciones competentes en la materia, así como el ámbito y la forma en la que las organizaciones con experiencia y que desarrollan programas financiados por las Administraciones Públicas en las labores de acogida y/o protección de las víctimas de este tipo de delitos pueden participar.

Conforme a lo establecido en el mencionado artículo 140 se aprueba el Protocolo Marco de Protección de Víctimas de Trata de Seres Humanos que fue suscrito el 28 de octubre de 2011 por los Ministerios de Sanidad, Servicios Sociales e Igualdad, Interior, Justicia, Empleo y Seguridad Social, la Fiscalía General del Estado y el Consejo General del Poder Judicial ${ }^{49}$. Un Protocolo que ha permitido reforzar los

\footnotetext{
46 Sobre la necesidad imperiosa de prestar apoyo y protección a las víctimas, resultan de interés las orientaciones dictadas por la Organización para la Seguridad y la Cooperación en Europa (OSCE) que han sido publicadas en el manual titulado "National Referral Mechanisms: Joining Efforts to Protect the Rights of Trafficked Persons".

${ }^{47}$ Téngase en cuenta que se prevé la asistencia sanitaria para las víctimas de la trata durante el período de restablecimiento y reflexión. Véase la Disposición Adicional Quinta del Real Decreto 576/2013, de 26 de julio, por el que se establecen los requisitos básicos del convenio especial de prestación de asistencia sanitaria a personas que no tengan la condición de asegurados ni de beneficiarias del Sistema Nacional de Salud.

${ }^{48}$ En este sentido, a nuestro parecer, será de gran utilidad la elaboración de protocolos de detección y denuncia de la trata de personas en los ámbitos sanitario, social y educativo. Y resulta positivo que el desparecido Ministerio de Igualdad haya realizado, con fecha 30 de junio de 2009, una convocatoria de subvenciones para la protección y asistencia integral de mujeres víctimas de la trata con una dotación económica de 2 millones de euros. Convocatoria que ha permitido subvencionar proyectos de creación de unidades móviles y pisos de acogida, impartición de formación para el empleo y la atención integral específica, entre otra, psicológica, médica o jurídica.

${ }^{49}$ En este sentido, hemos de valorar positivamente que ya en el año 2008 el Plan contra la Trata incluyera dentro del área relativa a las medidas de asistencia y protección a las víctimas, y como su objetivo primero, el garantizar la protección a las víctimas y a testigos en aplicación de la LOEX. En particular, se prevé elaborar un Protocolo de actuación y coordinación entre policía, fiscalía y órganos judiciales que
} 
canales de cooperación interinstitucional que resulta clave para una eficaz protección de la víctima. Prueba de ello resulta la previsión del procedimiento por el que, ante la existencia de indicios de trata en los procedimientos de solicitud de protección internacional, la Oficina de Asilo y Refugio pone tal circunstancia en conocimiento de la Comisaría General de Extranjería y Fronteras, aunque la tramitación de la solicitud de protección internacional sigue su curso.

Pero si queremos lograr la cooperación de la víctima no solo ha de extremarse el celo para proteger a la víctima directa de la trata sino que también hay que velar por la seguridad y protección de aquellas otras personas que se encuentren en España y que tengan relación con la víctima ${ }^{50}$.

En este contexto, han de activarse los medios de protección que puede decretar el Juez de Instrucción de conformidad con lo previsto en la Ley Orgánica 19/1994, de 23 de diciembre, de protección de testigos y peritos en causas criminales que permite acogerse a la condición de testigo protegido ${ }^{51}$. En este sentido, y entre otras, el artículo 2 de la citada normativa contempla la posibilidad de adoptarse las siguientes medidas: que no conste en las diligencias que se practiquen el nombre, apellidos, domicilio, lugar de trabajo y profesión, ni cualquier otro dato que pudiera servir para la identificación de los testigos y peritos, pudiendo utilizarse para ello un número o cualquier otra clave ${ }^{52}$; que éstos comparezcan para la práctica de cualquier diligencia utilizando cualquier procedimiento que imposibilite su identificación visual normal; y, que se fije como domicilio, a efectos de citaciones y notificaciones, la sede del órgano judicial interviniente, que será el encargado de hacerlas llegar de forma reservada a su destinatario ${ }^{53}$.

Aunque, conviene aclarar que, por motivos de índole variada, en ocasiones los programas de protección de testigos no se aplican por lo que es necesario incidir de forma especial en la necesidad de protección de las víctimas puesto que, por razones obvias, el riesgo que asume la víctima que denuncia es altísimo y no solo para ella sino también para su familia.

contemple al menos, los aspectos que a continuación se mencionan: información adecuada a las víctimas sobre sus derechos, servicios y recursos; protección de los datos identificativos de las víctimas en los atestados; mecanismos para proteger la intimidad de éstas en las vistas orales; medidas que faciliten los cambios efectivos de domicilio; mecanismos para facilitar la protección de familiares en el país de origen mediante comunicaciones rápidas entre organizaciones policiales; e, instrumentos de coordinación entre policía y fiscalía para articular la comunicación entre ambas.

${ }^{50}$ En este orden de cosas el último párrafo del art. 59bis.2 de la LOEX dice lo siguiente: “Con carácter extraordinario la Administración Pública competente velará por la seguridad y protección de aquellas otras personas, que se encuentren en España, con las que la víctima tenga vínculos familiares o de cualquier otra naturaleza, cuando se acredite que la situación de desprotección en que quedarían frente a los presuntos traficantes constituye un obstáculo insuperable para que la víctima acceda a cooperar"

${ }^{51}$ BOE núm. 307 de 24 de diciembre de 1994. Téngase en cuenta que, como apunta el Tribunal Supremo en sentencia de 28 de octubre de 1992, la víctima de un delito es un "testigo con un status especial". Sobre este particular, igualmente, resulta de interés la Ley Modelo sobre protección de testigos adoptada por la Organización de Naciones Unidas.

52 Sobre este particular, ECHARRI CASI, F. J., apuesta por la creación de un registro reservado de víctimas de la trata en el que figure tanto la identidad real como la ficticia otorgada a la víctima para evitar disfunciones a la hora de consultar datos ("La excusa ...", cit., pág. 17).

${ }^{53}$ En todo caso, no podemos pasar por alto que, como apunta GARCÍA, S., el acusado puede solicitar conocer la identidad del testigo, amparándose en la jurisprudencia del Tribunal Supremo, del Tribunal Constitucional e, incluso, del Tribunal Europeo de Derechos Humanos que prevé que el anonimato de los testigos puede provocar indefensión (“Inmigración ...”, cit., pág. 262). 
En el apartado tercero se incluye la posibilidad de denegación o revocación del período de restablecimiento y reflexión tanto por motivos de orden público como cuando se tenga conocimiento de que la condición de víctima se ha invocado indebidamente.

El apartado cuarto, contempla la posibilidad de que la autoridad competente exima a la víctima de responsabilidad administrativa estableciéndose, además, que podrá facilitársele, siempre a elección de la víctima:

Por un lado, el retorno asistido a su país de procedencia. Una opción que sitúa a la víctima en una situación verdaderamente compleja. Por una parte, porque la organización de traficantes expande sus tentáculos hasta el lugar de origen de la víctima. Y, por otra, porque la víctima si decide retornar a su país de origen debe de enfrentarse a problemas de variada índole, a saber, físicos, psicológicos, familiares, jurídicos o económicos. Y es que, entre otros muchos factores, hay que poner de relieve que las comunidades de origen menosprecian a las víctimas de la trata que han sido explotadas sexualmente. Unas víctimas que, además, en la mayoría de los casos, regresan en un estado de salud muy deteriorado y con serios problemas psicológicos. De modo que, estas víctimas soportan una doble carga: su propia situación de personas explotadas y la estigmatización y rechazo social que sufren. Circunstancias que sirven para defender la necesidad de que estos programas de retorno lleven aparejada la necesaria asistencia a la víctima en aras a la consecución de su reinserción en el país de origen.

O bien, por otro lado, la autorización de residencia y trabajo por circunstancias excepcionales de conformidad con el artículo 31.3 de la LOEX ${ }^{54}$. Nos situamos ante una vía que ofrece, en general, a la mujer extranjera en situación de irregularidad la posibilidad de regularizar su situación en España obteniendo, en concreto, una autorización de residencia temporal durante un año por razones humanitarias. Una posibilidad que queda abierta, entre otros, para las personas: extranjeras víctimas de ciertos delitos tipificados en el Código Penal; las que colaboren con las autoridades administrativas, policiales, fiscales o judiciales; personas extranjeras que acrediten sufrir una enfermedad sobrevenida de carácter grave que requiera asistencia especializada imposible de recibir en el país de origen; o las personas extranjeras que acrediten que el traslado al país de origen o procedencia, para solicitar el visado, implica un riesgo bien para él o para su familia. Sobre la posibilidad de obtener la autorización de trabajo por circunstancias excepcionales conviene subrayar que los empleadores que contraten a estas víctimas tendrán derecho desde la celebración del contrato a una bonificación mensual de la cuota empresarial a la Seguridad Social o, en su caso, por su equivalente diario, por persona contratada de 125 euros por mes durante un período de 2 años.

Sobre este particular, conviene poner de relieve que la LOEX contempla junto a la residencia por razones humanitarias la denominada residencia por razones de arraigo $^{55}$ y la residencia temporal por razones de protección internacional para aquellos

\footnotetext{
${ }^{54}$ Desarrollado reglamentariamente en el artículo 45.4.

${ }^{55}$ Respecto a la residencia por arraigo regulada en el artículo 45.2 del R.D. 557/2011, de 20 de abril, de desarrollo de la LOEX pueden diferenciarse los siguientes tres supuestos: la autorización de residencia temporal por arraigo laboral; el denominado arraigo social; y, la autorización de residencia por razones de arraigo para los hijos de padre o madre que hubieran sido originariamente españoles.
} 
extranjeros que hubieran obtenido el estatuto de asilado o refugiado así como para los desplazados ${ }^{56}$.

Así, si la víctima opta por solicitar la autorización de residencia y trabajo por circunstancias excepcionales deberán de adoptarse las medidas oportunas para procurar y facilitar su integración social. Sobre este particular, además, la Ley permite que la víctima sea eximida de presentar aquellos documentos necesarios para la tramitación de la correspondiente autorización de residencia y trabajo cuando su obtención implique un riesgo para la misma. Una previsión de especial relevancia cuando nos encontramos con este tipo de víctimas, esto es, ante la víctima de la trata de seres humanos habida cuenta de que, en la mayoría de los casos, las mafias dedicadas a este tipo de ilícito despojan a sus víctimas de la documentación cuando éstas llegan al país de destino.

Cierto es que este apartado cuarto incorpora una novedad garantista que puede animar a la víctima a colaborar con las autoridades competentes coadyuvando así a la lucha contra este tipo de delincuencia. Lo cual nos induce a mostrar un cierto optimismo puesto que, aunque, la exención de responsabilidad y la concesión de la autorización de residencia y trabajo se supedita al hecho de que la autoridad competente lo considere necesario en atención a la cooperación que la víctima preste para los fines de la investigación o de las acciones penales, también, dicha autorización podrá concederse atendiendo a su situación personal. De modo que además de la actitud colaborativa de la víctima su situación personal también puede dar lugar a la obtención de un permiso de residencia y trabajo. En este sentido, el problema radica en definir este último supuesto de hecho habilitante en base al cual puede eximirse a la víctima de responsabilidad y otorgársele una autorización de residencia y trabajo. El criterio de la "situación personal" de la víctima resulta ambiguo e impreciso y no figura entre los previstos en la ya citada Directiva 2004/81 para la expedición del permiso de residencia ${ }^{57}$. Pero en todo caso, valoramos positivamente esta incorporación puesto que la actitud colaborativa como título para obtener un permiso de residencia y trabajo por parte de la víctima plantea la injusticia de aplicar un tratamiento diferenciador entre aquellas víctimas que tengan más o menos información.

Y ya para finalizar, los dos últimos apartados, el quinto y el sexto, hacen referencia, respectivamente, a la aplicación de las previsiones analizadas también a los menores de edad incluyendo, como no podía ser de otro modo, una referencia expresa a velar por el interés superior del menor y a las condiciones de colaboración de las organizaciones no gubernamentales sin ánimo de lucro que tengan por objeto la acogida y protección de este tipo de víctimas. Apuntando el apartado sexto que las condiciones de colaboración de las organizaciones no gubernamentales sin ánimo de lucro que tengan por objeto la acogida y protección de las víctimas de la trata de seres humanos se fijarán reglamentariamente.

\footnotetext{
${ }^{56}$ Artículo 45.3 del R.D. 557/2011.

57 Tal y como prevé el artículo 8.1 de la Directiva 2004/81 para que se expida el permiso de residencia, “(...) los Estados miembros considerarán:

a) la conveniencia que presenta la prórroga de la estancia de dicha persona en su territorio a efectos de investigaciones o de acciones judiciales

b) si dicha persona ha mostrado una clara voluntad de cooperación, y

c) si dicha persona ha roto todas sus relaciones con los presuntos autores de hechos que pudieran ser constitutivos de alguno de los delitos a que se refieren las letras b) y c) del artículo 2".
} 


\section{ALGUNAS REFLEXIONES FINALES}

En las precedentes páginas se ha analizado la respuesta normativa articulada por el legislador de extranjería para combatir la situación de especial vulnerabilidad en la que se encuentra la mujer inmigrante en territorio español cuando ésta resulta víctima de una de las formas de criminalidad más execrables, a saber, la trata de personas. Esta respuesta se plasma en la regulación prevista en el artículo 59bis de la LOEX. El mencionado precepto contempla, entre otras, las siguientes previsiones: incorpora un mandato dirigido a las autoridades competentes para la adopción de las medidas necesarias en aras a la identificación de las víctimas; incluye el denominado "período de restablecimiento y reflexión" en el que la Administración deberá procurar subsistencia y protección a la víctima y durante el cual se le ofrece, en el supuesto de que se muestre dispuesta a colaborar en el procedimiento penal, la posibilidad de que se suspenda el expediente sancionador incoado o la ejecución de la medida de expulsión o devolución acordadas; y, contempla la exoneración de responsabilidad administrativa de la víctima pudiendo ésta elegir entre el retorno asistido al país de origen o la obtención de una autorización de residencia y trabajo por circunstancias excepcionales.

\section{Llegados a este punto debemos señalar las siguientes consideraciones:}

Primera, y respecto al mandato dirigido a las autoridades competentes para la adopción de las medidas necesarias para la identificación de las víctimas, puede constatarse que existen serias dificultades para llevar a cabo una efectiva labor de identificación.

Segunda, en relación con la concesión del período de restablecimiento y reflexión conviene matizar que la autorización de estancia temporal que se concede a la víctima en estos casos sigue estando inescindiblemente condicionada a la colaboración que ésta preste a las autoridades competentes encargadas de investigar y enjuiciar el delito.

Tercera, tanto la suspensión del expediente sancionador ya incoado o la inejecución de la sanción ya acordada como la exoneración de responsabilidad administrativa responden a la utilidad de la declaración de la víctima en su calidad de testigo.

Y cuarta, a nuestro juicio, la previsión que merece ser valorada positivamente es el hecho de que la autorización de residencia, además de poder otorgarse en función de las circunstancias personales que concurran en la víctima, lleve aparejada la de trabajo. La cuestión no es en modo alguno irrelevante, pues con ello se abre a la víctima la posibilidad de incorporarse regularmente al mercado laboral permitiéndole obtener los medios de subsistencia necesarios para su mantenimiento en territorio español.

El marco esbozado, nos permite señalar que las medidas acordadas por el legislador de extranjería han de ser calificadas de insuficientes puesto que el objetivo prioritario al que responde la reforma es la persecución del delito y la sanción del que lo comete quedando relegado a un segundo plano el de la protección y restitución de la mujer inmigrante víctima del delito. Una protección que goza además de importantes lagunas. Destacamos las siguientes: 
Por un lado, la falta de eficacia, en muchas ocasiones, de los programas de protección de testigos.

Por otro lado, la escasez de medios materiales y personales dispuestos para asegurar una asistencia integral de la víctima y conseguir que no se produzca su victimización. Ello exige, desde nuestro punto de vista, encarar el problema desde la perspectiva de la protección de los derechos humanos y no, únicamente, desde el enfoque que nos ofrece el control de los flujos migratorios.

Y, además, el hecho de que la protección de la víctima se condicione a que esta coopere con las autoridades en la investigación del delito $\mathrm{y}$, en su caso, con el procedimiento penal.

Ahora bien, siendo importante la restitución de la víctima, si se quiere combatir de modo eficaz esta forma de criminalidad debemos enfocarla adecuadamente superando la actual incoherencia existente entre la regulación de la trata en el contexto internacional y en el interno. Ello conlleva la necesidad de sintonizar o adecuar la regulación llevada a cabo por el legislador de extranjería con la prevista en los instrumentos internacionales ratificados por el Estado español. Dicho en otras palabras, es necesario que la mujer extranjera en situación de irregularidad víctima de la trata sea considera víctima de la violencia de género, puesto que esta es la caracterización que a esta forma de criminalidad se le dispensa ya en 1993 en el seno de NNUU. Y asimismo resulta clave reconocer la naturaleza sistémica o estructural de este tipo de violencia en coherencia con lo dispuesto tanto en el ámbito internacional como en el de la Unión Europea. En suma, es necesario abordar el fenómeno de la trata desde la perspectiva de género lo que a día de hoy no se hace ni por el legislador penal ni por el de extranjería. Y ello a pesar de que la Resolución 1325 del Consejo de Seguridad de NNUU sobre mujer, paz y seguridad complementada por las Resoluciones 1820, 1888 y 1960 insta a los Estados a aplicar la perspectiva de género.

Merece destacar el hecho de que cuando se comete el tipo delictivo de la trata al margen del bien jurídico afectado - la explotación sexual-, el sujeto activo que comete el delito somete y subordina, ejerciendo su rol dominante, a la mujer extranjera víctima a la más aberrante de las formas de explotación, a saber, la sexual precisamente valiéndose de su situación de superioridad. Esto es, sostener que la trata con fines de explotación sexual es una forma de violencia de género significa que la trata es otra de las manifestaciones en las que se expresan y siguen perpetuándose las relaciones desiguales de poder o la jerarquía entre los sexos. De todo lo dicho, cabe deducir que la trata con fines de explotación sexual - y máxime en el caso de que la víctima sea la mujer inmigrante en situación de irregularidad administrativa puesto que en este caso interseccionan diferentes vectores discriminatorios-, hemos de situarla en un contexto de desigualdad o de violencia estructural donde afloran las conductas dominantes del varón situando a la mujer víctima en una situación de subordinación.

En suma, la regulación penal de la trata con fines de explotación sexual y las medidas que el legislador de extranjería diseña en aras a la restitución de la víctima no permiten aflorar la verdadera dimensión de este tipo de criminalidad invisibilizando así que nos situamos ante una forma de discriminación estructural. Y mientras no se aborde el fenómeno desde la óptica que nos ofrece la perspectiva de género no podremos adoptar las medidas adecuadas para erradicar de forma eficaz la trata. No parece haber 
dudas sobre el hecho de que la trata es un tipo de violencia de género $-\mathrm{y}$ esta es la forma más dura en la que se manifiesta la construcción social de los géneros- que, por supuesto, no queda restringida al ámbito de lo doméstico como prevé la Ley $1 / 2004$, de 28 de diciembre, de Medidas de protección Integral contra la Violencia de Género. Ya para finalizar, cabe destacar que la protección de la víctima de la trata con fines de explotación sexual desde un enfoque basado en la perspectiva de género permitirá poner el foco de atención en la discriminación sistémica que esta sufre y solo así se podrá combatir eficazmente la discriminación y con ello se logrará avanzar en pos de una sociedad más justa e igualitaria.

\section{BIBLIOGRAFÍA}

BALES, K., La nueva esclavitud en la economía global, Siglo XXI de España Editores, 2000.

BAUCELLS I LLADÓS, J., "El tráfico ilegal de personas para su explotación sexual”, RODRÍGUEZ MESA y RUÍZ RODRÍGUEZ (Coords.), Inmigración y sistema penal. Retos y desafios para el S. XXI, Tirant Lo Blanch, Valencia, 2006, págs. 173-202.

BERCOVITZ RODRÍGUEZ-CANO, R., "La dignidad de las víctimas de delitos", Aranzadi civil, núm. 6/2010, págs. 11-14.

BOLDOVA PASAMAR, M. A., "Trata de seres humanos, en especial menores", Revista de Derecho Migratorio y Extranjería, núm. 23, año 2010, págs. 51-112.

CONCEPCIÓN SALVADOR, R., Violencia de género en España, Francia, Reino Unido e Italia ¿Un concepto global?, Dykinson, Madrid, 2015.

DE LEÓN VILlALBA, F. J., Tráfico de personas e inmigración ilegal, Tirant Lo Blanch, Valencia, 2003.

ECHARRI CASI, F. J., se refiere a "una de las formas de vulneración de los derechos humanos más execrables", ("La excusa absolutoria en el delito de trata de seres humanos como mecanismo de protección de las víctimas", Diario La Ley, n ${ }^{\circ}$ 9434, 12 de junio de 2019, págs. 1-26.

FERREIRO, X., La víctima en el proceso penal, La Ley, Madrid, 2005.

GARCÍA ARÁN, M., Esclavitud y tráfico de seres humanos, Tirant Lo Blanch, Valencia, 2006.

-Trata de personas y explotación sexual, Comares, Granada, 2006.

GARCÍA SEDANO, T., "Sería subsumible el delito de trata de seres humanos en la Ley 1/2004, de 28 de diciembre?", La Ley 833/2016, págs. 1- 19.

GARCÍA VÁZQUEZ, S., "Inmigración ilegal y trata de personas en la Unión Europea: la desprotección de las víctimas", Revista de Derecho Constitucional Europeo, núm. 10 /2008, págs. 231-275. 
GARCÍA VÁZQUEZ, S. y FERNÁNDEZ OLALLA, P., La trata de seres humanos, Centro de Estudios Políticos y Constitucionales, Madrid, 2012.

HERNÁNDEZ PLASENCIA, J., "El delito de tráfico de personas para su explotación sexual", CAPELLO, L. (coord.), Inmigración y Derecho Penal, Tirant Lo Blanch, Valencia, 2002, págs. 237-254.

JUANES PECES, A., "El delito de trata de seres humanos en el proyecto de reforma del Código Penal de 1995”, Actualidad Jurídica Aranzadi, núm. 803 /2010, págs. 1-6.

LUZÓN CÁNOVAS, M., La tipificación penal de la organización y el grupo criminal. Problemas concursales, Revista El Derecho, Lefebre, 2011, págs. 1-21.

MARTOS NUÑEZ, J. A., "El delito de trata de seres humanos: Análisis del artículo 177 bis del Código Penal”, Estudios Penales y Criminológicos, Vol. XXXII, 2012, págs. $97-$ 130 .

MAQUEDA ABREU, M. L., "El tráfico de personas con fines de explotación sexual", Jueces para la Democracia, núm. 38 /2000, págs. 25-29.

- El tráfico sexual de personas, Tirant Lo Blanch, Valencia, 2001.

- "La violencia de género: entre el concepto jurídico y la realidad social", Revista Electrónica de Ciencia Penal y Criminología, 20 de enero de 2006, págs. 4-11.

NICOLÁS, G., "Migraciones femeninas y trabajo sexual. Concepto de trabajo precario versus trabajo de mujeres", R. BERGALLI (Coord.), Flujos migratorios y su (des)control. Puntos de vista pluridisciplinarios, Anthropos, Barcelona, 2006, págs. 229-260.

PÉREZ CEPEDA, A. I., Globalización, tráfico internacional ilícito de personas y derecho penal, Comares, Granada, 2004.

PÉREZ FRANCESCH, J. L., “Cooperación policial y judicial en la Convención de Prüm”, Revista de Derecho Constitucional Europeo, núm. 7 /2007, págs. 119-136.

RUÍZ LÓPEZ, C., "La reparación en el delito de trata de seres humanos con fin de explotación sexual. Una propuesta de regulación en España”, La Ley Penal, núm. 127, julio-agosto, 2017, págs. 1-19.

SERRA CRISTÓBAL, R. y LLORIA GARCÍA, P., La trata sexual de mujeres. De la represión del delito a la tutela de la víctima, Ministerio de Justicia, Madrid, 2007.

SERRA CRISTOBAL, R., "La trata de mujeres como una de las formas más atroces de violencia contra la mujer", en la obra Estudio Integral de la violencia de género: Un análisis teórico práctico desde el Derecho y las Ciencias Sociales, M Martín Sánchez (Dir.), Tirant lo Blanch, Valencia, 2018, págs. 271-292.

ZUGALDÍA ESPINAR, J. M. (Dir.) y PÉREZ ALONSO, E. J. (Coord.), El Derecho Penal ante el fenómeno de la inmigración, Tirant Lo Blanch, Valencia, 2007. 